\title{
Student Attraction, Persistence and Retention in STEM Programs: Successes and Continuing Challenges
}

\author{
Alec Sithole ${ }^{1}$, Edward T. Chiyaka ${ }^{2}$, Peter McCarthy ${ }^{3}$, Davison M. Mupinga ${ }^{4}$, Brian K. Bucklein ${ }^{1} \&$ Joachim \\ Kibirige $^{5}$ \\ ${ }^{1}$ Department of Computer Science, Mathematics and Physics, Missouri Western State University, St Joseph, \\ Missouri, USA \\ ${ }^{2}$ Department of Health Policy and Management, College of Public Health, Kent State University, Kent, Ohio, \\ USA \\ ${ }^{3}$ Mathematics Department, Lane College, Jackson, Tennessee, USA \\ ${ }^{4}$ Teaching, Learning, and Curriculum Studies, Kent State University, Kent, Ohio, USA \\ ${ }^{5}$ Department of Economics, Political Science and Sociology, Missouri Western State University, St. Joseph, \\ Missouri, USA \\ Correspondence: Alec Sithole, Department of Computer Science, Mathematics and Physics, Missouri Western \\ State University, St Joseph, Missouri, USA. E-mail: asithole@missouriwestern.edu
}

Received: December 5, 2016

Accepted: December 13, 2016 Online Published: January 16, 2017

doi:10.5539/hes.v7n1p46

URL: http://dx.doi.org/10.5539/hes.v7n1p46

\begin{abstract}
Low student enrollment and high attrition rates in Science, Technology, Engineering, and Mathematics (STEM) education are major challenges in higher education. Many STEM entrants end-up switching their majors to non-STEM fields, perform poorly relative to their peers in other programs, and/or drop out of college without earning any academic qualification. Therefore, it is important to examine strategies for reducing attrition in STEM programs. This paper reviews the major factors impeding student interest, success, and persistence in STEM programs, and current institutional practices aimed at addressing these issues. Suggested institutional strategies to improve persistence in STEM programs and their implications that are discussed in this paper include: provision of orientation programs, adoption of early warning systems, Mathematics review sessions, creation of student learning communities, professional development of faculty, as well as collaborative and outreach programs. It is hoped that this review will encourage debate toward solving the major challenges facing STEM education.
\end{abstract}

Keywords: attrition, institutional factors, persistence, motivation, self-efficacy, STEM education

\section{Introduction}

\subsection{The Problem and Its Magnitude}

In this age and era of scientific triumph where even five-year-olds are not only controlled by technology but actually do operate and maneuver technological equipment such as video games, telephones, etc., it is an irony that the fields that make life so exciting, convenient and "cool" are also the same fields that are least attractive to student career pursuits. How come students are not flooding into these fields to become the "Einsteins" of tomorrow or inventors of the next generation of video games, or the next computer "wizards"? Even more puzzling is the fact that all this is happening during a time in history when jobs in technical fields requiring STEM skills are quite abundant. STEM jobs in the U.S. are projected to increase by 8.7 percent for the period 2010-2020 (National Science Foundation, 2014), and the demand for manufacturing jobs requiring STEM skills below or on the bachelor's level remains high. Morrison et al. (2011) reported that in the US, almost 600,000 technical positions in the manufacturing sectors remain open due to shortage of candidates with STEM skills. Based on the projections reported by Giffi et al. (2015), the shortage is likely to reach two million over the next decade if there is no further intervention.

Yet the number of students with interest in STEM remains substantially low (Chen \& Soldner, 2013). This seems to defy logic, given that the single most common concern students express before deciding on a major is their 
chances of finding a job with a degree in a given field. Past experience also shows that the more marketable a given specialty/field is, the higher the enrollments in the relevant programs. Nursing and Business are prime examples. STEM programs, however, are an anomaly in this regard. The majority of students who enroll in STEM-related majors do not graduate with a STEM degree. Furthermore, based on a three year study of student interviews and enrollment patterns, Correll, Seymour and Hewitt (1997) reported that about 40 percent of those who enroll in engineering change their programs to non-science and non-technical majors; 50 percent drop out of physical and biological sciences and 60 percent drop out of mathematics programs.

There has been considerable research to determine the factors that influence or discourage the students' choice of STEM-related studies (Cleaves, 2005; Ost, 2010; Tai, Qi-Liu, Maltese, \& Fan, 2006). These are discussed in later sections: student, institutional, and other factors. According to Tai et al. (2006), science programs have experienced considerable declines in the number of graduates. Despite the fact that STEM programs have contributed immensely to our daily livelihoods, student interest toward these sciences remains low, worldwide. In the U.S., the physical sciences are among the least popular fields, attracting only about 3 percent of students that enroll in STEM fields (Chen \& Soldner, 2013). Also, academic performance and overall college success of the U.S. students was found to be lower for STEM graduates when compared to those in Australia, China, England, Japan, and Russia (Sunstein, 2013).

The two groups of students with high dropouts are female students and under-represented minority students (National Science Board, 2008). Thus, gender and race/ethnicity seem to be significant factors. The reasons why, and the overall impact these factors have on STEM programs are discussed under the section on social factors. In general, however, the overall major contributing factors to STEM attrition have been deficiencies in analytical and mathematical skills, which are critical to success in STEM programs (Mattern, Radunzel, \& Westrick, 2015). According to Rogers and Ford (1997), students' dislike of STEM programs is a result of several unpleasant experiences in science courses. These experiences may include: poor teaching techniques by some instructors; lack of interest in working hard, lack of students' self-interest, social backgrounds, poor institutional support mechanisms, etc. (Cheryan, Master, \& Meltzoff, 2015). To all this is added the media's negative stereotyping of STEM-related programs (Rogers \& Ford, 1997) which reinforces the already culturally entrenched view that the "Sciences" are extra hard subjects and are suited for a very select few persons with extra intelligence. Furthermore, some instructors concentrate only on non-pedagogical research and publication, with almost no effort to improve teaching techniques and virtually no attempts to offer initiatives to improve students' interest in the courses. It seems to be taken for granted that students will naturally, somehow by "osmosis", or mere proximity, develop positive attitudes toward science as they take science classes.

A recent study noted that 45 percent of incoming freshmen had significant problems with Mathematics, which is central to competencies in STEM programs (Noel-Levitz, 2013). Other studies have shown that the majority of STEM students would end up dropping out, fail, or change their majors to professional programs, social sciences, humanities or business (Ost, 2010). According to the 2010 National Survey on STEM Education (STEM Market Impact, LLC, 2010), STEM education in the U.S. faces a number of challenges which include insufficient funding in K-12, lack of professional development for STEM teachers, and inadequacy of STEM education in $\mathrm{K}-8$. While all this is not new, what is puzzling is its continuation in light of the fact that the last few decades have seen technology take over virtually every aspect of our lives and we have accepted and encouraged that to become the norm. Logic, however, seems to suggest that one would have expected the contrary. This is akin to a situation where people are interested in eating food but are not interested in taking part in its production. On the other hand, people may get more interested in and become even more dependent on a particular type of food but if the factors keeping them away from its production remain unchanged, it won't make any difference. If people are "afraid" of Mathematics, for example, it does not matter how much their lives depends on Mathematics, they will still be afraid of Mathematics. Poor performance in Mathematics, for example, is not an inherent problem of some people's brains but it is, for the most part, culturally inculcated. Why there are still only a few women and ethnic minority surgeons and pilots does not prove anything other than a culturally structured social pattern resulting from specific historical experiences such as patriarchy and other parameters of social inequality such as social class and race/ethnicity. Thus, the disjunction between availability of opportunities in STEM careers and the lack of enthusiasm to go into those careers is a paradox that needs to be disentangled. This must also be seen in the context of the fact that STEM jobs are not only more available but also pay far higher salaries than jobs in other fields. Thus, the inhibiting factors against STEM careers seem to be powerful enough to even counter the monetary rewards and social prestige that comes with being a "Scientist". In most familiar situations, this would be "a risk worth taking" but in this case it is a "risk worth avoiding". 
Despite these challenges, however, there are institutional measures being taken to improve STEM education, and these are discussed under the section on "institutional factors". Failure to promote STEM programs will result in fewer scientists and engineers in the next generation. A major step will be to devise ways that demystify Science. According to (Sithole, Kibirige, Mupinga, \& Chiyaka, 2016), science has traditionally been treated as something of a mystery. It is dressed in terminology and symbols that remove it from the human world to the world of total abstraction. Yet, the objects of science are naturally pre-made and scientists are ordinary people who have ventured to try to understand the existence, and properties of the natural objects and to use that understanding to try to utilize the objects to solve the problems and serve the needs of humans and those of other related species. Until science is brought down to the level of the people, until we stop looking at scientists as if they are a special type of people, until we become aware that scientists are dealing with the very same things we deal with in our daily lives and as long as we keep science mystified and detached from the people, scientists are going to slowly become an "endangered species". The issues addressed in the study, therefore have far reaching implications than may be immediately perceived.

\subsection{Scope of the Study}

High attrition, low motivation, and low entrant numbers are big challenges for STEM education growth. Examining the reasons for low student persistence and retention, and how to increase motivation and retention rates remains a top priority in STEM education. The NGSS (2013) set new collaborative and state-led standard goals to support solid K-12 science education in the US to address STEM career needs, such as "coupling practice with content", "instructional flexibility", explicit use of "crosscutting concepts", and application of "disciplinary core ideas". While these core standards form a good road map for transforming K-12 STEM education, there is need to develop practical steps to achieve those standard goals. The aim of this study was to review the successes and failures of past and present interventions used to support student retention and persistence in STEM courses in order to identify practical strategies for strengthening them and their institutional implications.

\section{Methodology}

A narrative literature review approach was used to describe the current state of STEM education in the United States. Specifically, the approach allowed the researchers to review the latest developments in STEM, including identifying factors that promote and/or impede progress in STEM education, and some of the institutional measures in place aimed at reducing attrition in STEM programs and their implication. This article identifies and discusses some of the challenges being faced by students in integrating into STEM programs, engagement, and persistence in STEM education. These challenges, which are both individual and institutional are classified into three main areas: 1) Institutional factors, 2) Student factors, and 3) Other factors. Based on a critical analysis of these factors and current efforts to address them, recommendations for improvement in institutional STEM student support systems and their implications are presented. In addition, different efforts from selected organizations like the National Science Foundation (NSF) and the federal government that seek to attract more students to scientific careers are discussed as well.

\section{Institutional Factors}

In the sections below, institutional factors that affect student persistence, motivation, self-efficacy, and success are presented in detail.

\subsection{Student Course Load}

Griffith (2010) found a positive association between high academic performance with low dropout and high graduation rates in STEM programs. A study by Sklar (2014) also reported evidence of strong relationship between high first-year college GPA and low graduation risk, and suggested the need for institutions to place more emphasis on freshmen engagement. A survey by Chen and Soldner (2013) found that on average the STEM grades were relatively lower by at least one grade point than non-STEM grades. Whether the difference in these grades is related to the inherent demand for more work due to high course loads or rigor in STEM programs is not well known. However, there is a general concern that STEM programs do not give students adequate time for extracurricular activities. Both these concerns and the differential in grades could be contributing factors to STEM dropouts or switch-outs. In addition, laboratory part of the course is often coupled with their respective courses but with no direct credit assigned to them. For example, a course in physics or chemistry can have two and a half hours of lectures three days a week in addition to two "Lab" hours a week but only get four credit hours. This must also be seen in view of the fact that the "labs" cost an additional fee which can be as much as $\$ 100$ or more per class. In this day and age where maximum rewards are expected with 
minimum effort, within the shortest time possible, the students' disjunction between work load and expected corresponding "rewards" seems to hold much credibility.

\subsection{Academic Advising}

Academic advising is a pivotal process for a student's education and career. Berdhal (1995) reported that initial advising is very instrumental in alleviating fears and concerns about the student's success. Student advising processes which include integration of curriculum with career and life goals, sharing of responsibility in monitoring progress, and referring to resources for non-academic issues and co-curricular activities have been shown to be important factors in a student's success (Berdhal, 1995). Academic advising is a complex process. Every student is unique and requires advising that is geared to their individual circumstances and needs. In other words, no shoe can fit all foot sizes. Ironically, the more variations in the student circumstances, the more the advising process needs to be organized and structured. In most cases, however, academic advising seems to be a disjointed process. In some large institutions, for example, freshmen are simply randomly allocated to faculty advisors regardless of academic discipline. A Physics professor advising a Psychology intended major student, and vice versa. Much more so, however, the complexity of factors the variety of students bring to the table over time clearly warrants some basic structuring of the advising process. For example, in a field like Mechanical Engineering where not only the majority are men but are almost simply expected to be men, what do we expect to happen in an advising encounter between a male Engineering professor and a female aspiring Mechanical Engineering student? This is only one illustration using gender but the variety of potential sources of complication in the advising process is virtually infinite; from age, to social class, to height, to lifestyle, to sexuality, to race, physical disability, etc. Just like being a doctor, patients come in all variegated forms and each patient is unique, but doctors must have some unified training in order to systematically address these otherwise unpredictable situations. Likewise, given all the student variations, all the more reason for the need for an advising framework which a systematic structure which we can use to address the unique situations. As it is today, however, in most institutions, there is hardly a systematic form of training for faculty advisors. It seems to be mostly a matter of figuring out what courses to take when and, therefore, paving out a road-map to graduation.

The implications of all this, therefore, is that institutions need to have mechanisms that support faculty development in students' advising. Another dimension is to encourage frequent student-professor face-to-face interactions. The developmental advising model is student-centered and might include helping students integrate life, career and educational goals and is believed to be more effective compared to the prescriptive advising model which uses a top-down approach (Smith \& Allen, 2006). The only major problem here would be lack of personnel. Most institutions are "spread thin", when it comes to faculty personnel and this involves financial implications. Ideally, however, this would be the recommendation.

\subsection{Pedagogy}

Various studies have indicated that blending courses could lead to better student performance, perceptions, and attitudes toward the course, and higher attendance rates (Riffell \& Sibley, 2004). Computer-based technologies have been successfully incorporated into traditional classes to supplement face-to-face instruction. Such activities include class discussions and virtual pre-laboratories using computer simulated activities, among others. From their study, Garnham, Kaleta, and Sudzina (2003) indicated that incorporating online activities into classes could motivate students in introductory classes. In addition, a website for the classes would also be helpful. However, maintaining and operating a viable course site adds financial stress to some institutions, in addition to the considerable amount of time needed to incorporate online activities into the traditional face-to-face format.

Education and learning are dynamic processes. Likewise, while facts per se may be fixed (for example, the law of gravity), knowledge itself is not static. Knowledge changes according to changes in the wider society and according to the tools available to a given people. As noted elsewhere (Sithole et al., 2016) culture shapes knowledge, including scientific knowledge. The facts may be the same but their interpretation will depend on the cultural perceptions of the people amongst whom they occur. For example, thunder is a factual physical phenomenon that is usually associated with lightning. Yet, under different cultures it has different meanings. People who experience a lot of lightning and thunder are more likely to worship the "God of Thunder". In that case, culture determines what the factual aspect of thunder means. However, as cultures change, the same phenomenon of lightning is interpreted as a sudden atmospheric electrostatic discharge. The same phenomenon of lightening could also be seen in some cultures as "God being angry". Likewise, while the principles being taught in any subject are the same, their interpretation and utilization changes over time. As generations change over time and space, the world, the same world, is viewed in newer and different ways. 
Education, therefore, cannot be conducted as if it is frozen in time. We must adjust our pedagogical approaches to meet changes as they occur. We must face the fact that society changes, and dramatically so; from the technological tools available to us, to the nature of the people, including students. Education is a service activity and must, therefore, be responsive to the changing needs of its clientele. We must, therefore, devise ways of keeping the knowledge not only relevant but also appealing to the generation of students we serve. In that regard, several pedagogical approaches have been devised to motivate students to learn science, including use of magazines/newspapers (Sithole et al., 2016).

Instructional practices in STEM courses are constantly being reviewed and there have been renewed efforts in this perspective. Sponsorships from organizations like the NSF and NAS have focused on the reform of STEM instruction in the college classroom. According to Dancy and Henderson (2008), most of the money has been spent on research and development but very little effort has been targeted toward understanding and improving the integration of the outcomes from research in classrooms (Chalmers, 2013), identified three important themes in the outcomes of science: (a) problem-solving; (b) scientific reasoning; and (c) demand for evidence to validate claims. Majoring in STEM improves problem-solving skills, scientific and logical reasoning skills, and quantitative reasoning. These skills help students to develop the ability to support their conclusions using well-reasoned arguments. However, on the other side of the aisle, the scant connection between curricula and career needs in STEM programs makes these disciplines less attractive than other programs. In particular, in STEM there is more protracted emphasis on academic mastery of concepts than career applications and relevancy. This has led to low-paying part-time careers with no job security. Instructional practices must, therefore, be adjusted to meet these challenges.

\section{Student Factors}

Some of the challenges faced by students in STEM education are inherently dependent on student classroom preparation, and attitude. These issues are presented in the next sections.

\subsection{Mathematics Proficiency}

The student's need for high mathematics proficiency in STEM is well-documented (Rapoport, 1973). Lack of Mathematics skills results in poor basic numerical manipulation which leads to low confidence and failure. Mathematics proficiency describes the mastery in the interpretation and use of Mathematics concepts. According to Hewson (2011), "students who freeze at the sight of numbers or equations will most certainly underperform" in STEM. Hewson (2011) further stated that mathematics studied independently of applications remains abstract, dull, and difficult.

Mathematics is used every day in STEM as a tool to understanding the laws of nature and other concepts in these disciplines, which are often written in mathematical language. Examples of such concepts are vectors, logarithms, complex numbers, basic algebra, and calculus, which are often used in introductory physical science courses. In upper-level courses, more complex Mathematics concepts are required. For example, quantum mechanics, statistical mechanics, analytical mechanics, and electromagnetism require higher order Mathematics proficiency to understand them. So, how can we engage more students in STEM programs? Can students with poor Mathematics skills solve Mathematics problems in higher education?

Often, the struggles with the Mathematics concepts and/or a negative attitude toward Mathematics plays crucial roles in the success or failure of students (Popham, 2005). Clearly, success in STEM strongly depends on the knowledge and interest in analytical skills. Some of the major courses/topics in which students usually show mathematical deficiencies include trigonometry, vector algebra, logarithms, complex numbers, calculus, graphs and equations, and statistics, among others. Although the levels of expectations vary across disciplines, students need adequate preparation and knowledge in these topics as prerequisites before taking STEM courses.

According to Geary (2013), students' challenges in learning Mathematics can be due to slowness in the development of the cognitive mathematical representations, associating symbols to the physical quantities, and lack of mathematical logical reasoning. So, do students good in Mathematics, also perform best in STEM? Not always; because some students with good grades in Mathematics still find it difficult to apply that knowledge in science, engineering, and technology classes. Hewson (2011) agrees that some students with good grades in Mathematics may not do well in sciences, engineering, and technology because of lack of confidence and/or interest. Also, there is a high degree of variance in Mathematics proficiency needed for different courses in STEM programs. For example, programs such as physics, chemistry, geosciences, materials science, meteorology, and astronomy, have different approaches in mathematical treatment of problems and difficulty. 


\subsection{Studying Habits/Academic Engagement}

Would changing study habits change students' interest towards STEM? Various studies have shown that studying habits determine the academic performance of students (Stinebrickner \& Stinebrickner, 2007). But how, do study habits differ across different disciplines? Would studying for STEM courses differ from non-STEM courses, and if so, how? Understanding study habits could be the foundation to motivate students to change their attitude towards learning STEM. Typically, studying STEM courses requires more time of study than most courses due to laboratory course requirements and research obligations. Moreover, some courses may demand more concentration and take more time to learn than others; this is typically so with learning new Mathematics concepts. While there are some habits that can be developed or changes made through coaching, others require a change of attitude and personal commitment. Still, there are important questions that remain unanswered. What role can instructors take to cultivate student's interest towards STEM? Can instructors influence the choice of study partners? Most often, students who befriend peers in a different program with more "free" time end up getting discouraged and eventually losing interest in time-intensive STEM programs.

\subsection{Peer Mentoring Programs}

Peer mentoring enables new students to have the opportunity to learn a specific experience(s) from the older students. Peer mentoring is a form of learning community (LaFee, 2003; Miller, 2000; Smith, 1993) in which students meet and learn from each other. Peer mentors provide education and support opportunities to individuals. The peer mentor may challenge the mentee with new ideas, and encourage the mentee to move beyond the things that are most comfortable.

Based on our experiences, most academic peer mentors are selected based on faculty's recommendations. The selection criteria often include the student's sensibility, confidence, reliability, and availability, as well as Grade Point Average (GPA). Colvin and Ashman (2010) explain that successful peer mentoring in higher education settings is the results from relationships among students, mentors, and instructors. They found that mentors' roles include peer leader, learning coach, and student advocate. Benefits identified include mentors reapplying concepts in their own academic lives and developing connections among mentees. Their results indicate that mentors also stand to benefit from the mentor/mentee relationship. They (mentors) develop friendships through their participation in the programs and are satisfied from helping new students. Another important benefit is that this program can be an additional source of income for the mentors. However, they also observed a very noticeable risk: mentees often become over-dependent on mentors, to the extent that they sometimes expect mentors to help them in everything related to their academics, which is not helpful to the academic growth of the mentees.

Peer mentoring can often help new students to adapt more easily to new academic environments. Also, the mentor-mentee relationship gives the mentee a sense of being connected to the larger community and a relaxed peace of mind in what otherwise would have been a stressful situation, which could lead to failure and eventually dropping out of academic programs or switching programs. Since mentors are selected based on the criteria of students' strong academic standing, they also serve as positive role models for their mentees, directing them towards academic and social success. Thus, mentors provide encouragement, advice, and friendship to students.

\subsection{Time Management Skills}

Time management plays a key role in shaping the attitude of students toward the course. Laboratories and research take most of the student's time, and thus reduce time for study and social activities, or may cause the students to overwork and become exhausted. A student who sleeps less hours often shows signs of stress (Hershner \& Chervin, 2014), disorientation and inattention during lectures. Most students across disciplines constantly struggle to balance time, yet even more time is needed in the sciences. Often, most students find themselves in a predicament where course activities take more effort and time than they had originally anticipated. This is far more of a nightmare to students, especially to those who work to pay their own tuition than their peers who rely on their parents for financial assistance. Therefore, institutions should support initiatives put in place to help students balance their academic and social needs, which may go a long way towards helping students in this respect.

\subsection{Student Motivation and Self-Efficacy}

Some students require inspiration, stimulation, and challenges, while others are naturally enthusiastic about the learning process. There are two major classes of motivation based on the reasons for accomplishing any given task: intrinsic motivation and extrinsic motivation. Intrinsic motivation refers to doing something because of inherent interest. The motivation force, here, is "interest". Without interest in what students do on academic 
work, they do not realize them as important to try and solve. For example, students may not appreciate why determining the maximum point of a curve is important if the concept has no meaning in real life to them. Extrinsic motivation, on the other hand, refers to completing a task for a gain (Ryan \& Deci, 2000).

Intrinsic motivation has emerged as the favorite among educators because it leads to desirable student learning outcomes and creativity (Ryan \& Deci, 2000). According to Ryan and Deci (2000), extrinsic motivation makes students "complete tasks with resentment, resistance, and disinterest or, alternatively, with an attitude of willingness that reflects an inner acceptance of the value or utility of a task" (pp. 54-67). This, they argued, was because the student feels externally propelled rather than doing it through self-motivation. Understanding these different types of motivation helps educators to identify the best methods of motivating students towards STEM programs.

According to Bandura (1978), the ability to persist in the face of aversive experiences and obstacles is dependent on the strength of personal self-efficacy. In this study, he proposed that personal self-efficacy was mostly driven by psychological state, personal accomplishments, verbal persuasion, and vicarious experience. These factors are important in enhancing motivation and performance attainment (Bandura \& Locke, 2003). In addition, the level of confidence for attaining specific goals determines the ability of a student to persist (Bong \& Skaalvik, 2003). In STEM education, studies indicate that students with high self-efficacy were likely to perform better and persist longer than their peers with lower self-efficacy (Rittmayer \& Beyer, 2008).

As noted in the following section, there are other factors that affect student success: early motivation; pre-secondary education curricula; out-of-field instruction; and social factors.

\section{Other Factors}

\subsection{Inspiring the Young}

According to Tai et al. (2006), students with expectations for a science related career are 3.4 times more likely to earn physical science and engineering degrees than students without similar expectations. This shows that efforts that seek to motivate students to develop the knowledge and skills required to pursue STEM courses in high school need to be increased. Additionally, students who have been exposed to enrichment programs like the Student Science Enrichment Program (SSEP) were shown to be interested in participating in a similar program in future and more interested in learning science (Burroughs Wellcome Fund, 2010). Students who participate in these initiatives are more motivated to pursue careers in STEM fields and the participation helps them decide on their future careers while they are still at high school or even earlier.

\subsection{High School Curricula}

The decision of students to enroll in STEM as a freshman is also dependent on their high school experiences. Currently, critical skills and basic mathematics competency (particularly algebra and trigonometry) among the majority of students entering college needs improvement. The low proficiencyin basic skills calls for the need to bridge high school and college science curricula. While most students can easily handle numerical calculations with the aid of their calculators, they lack algorithmic and Mathematics developmental skills, which limit their ability to solve non-numeric problems or apply the knowledge to real-life situations.

\subsection{Out-Of-Field Teaching in High and Middle Schools}

In many cases, high school and middle school teachers are assigned to teach subjects in which they have no background training. Low enrolment and graduation rates in colleges can also be traced back to the lack of middle- and high-school STEM teachers. The shortage of educators for STEM subjects force administrators to assign teachers to teach subjects outside of their areas of expertise. According to Morton et al. (2008), in 2007, about 30 percent of public middle-school science teachers taught subjects that they did not major in during college. Among them, 36 percent of Mathematics teachers were neither certified nor qualified to teach Mathematics. Similarly, in chemistry and physics, nearly 30 percent had no certification to teach these subjects; and about 50 percent teachers of earth science were not qualified.

Out-of-field teaching is generally thought to be a problem of poorly educated teachers (Ingersoll, 1998), which can be remedied by increasing the rigor in standards for teacher education and training. Another school of thought is lack of academic coursework, which leads to the idea of requiring preservice teachers to complete an undergraduate major in an academic specialty. Improved standards in teacher education programs and completion of an undergraduate major are imperative, but there is little or no help if the teachers are assigned to teach different subjects (Ingersoll, 1998). 


\subsection{Social Factors}

Individuals are a reflection of what they have been surrounded with. Our perceptions of situations and their interpretation are socially determined. Thus, child socialization is very important in determining what we become. Gender roles provide a prime example. Prior to modernity, people depended on tasks that involved a lot of physical strength. Since men have more body muscle and, therefore, more physical strength, these tasks were dominated by men. Men also became the dominant gender in a system known as patriarchy that is prevalent in most cultures around the world. Today we still have tasks that are divided on the basis of gender. Yet these tasks have nothing to do with body strength. Until fairly recently, being a doctor was almost exclusively a male job while being a nurse was almost exclusively a "female" job. Yet these tasks are not any different from each other in terms of requiring physical strength or not. Ironically, it is nurses, not doctor who do the "heavy" work of lifting, moving, and turning the patient, rolling heavy equipment, etc.! Being a pilot is not based on one's ability to lift an aircraft into the air. In fact, it is one of the tasks that barely require any form of strength as long as one can co-ordinate the movement of their fingers to manipulate buttons and switches. Yet some jobs have been culturally defined as "male" or "female". Thus, since most STEM careers have been placed under "male" identity, only a few "brave" women end up in those careers. Thus, the social factor of gender can, to a large extent, explain the preponderance of the low numbers in STEM programs and careers.

What is true of gender is also true of other parameters of social inequality such as race/ethnicity and social class. Traditionally, most people in STEM careers were those from well-to-do and predominantly "white" families. In many people's minds it became the norm, the way things are and the way things were expected to be. As such, like women, the less well-to-do and other minorities steered away from the pursuit of the programs. STEM programs are more expensive than other programs and this historically, has been the reserve of those who could afford the financial cost.

Yet even when we remove these confounding factors of gender, social class, ethnicity, etc., the numbers in STEM programs and careers are still low. This reaffirms the culturally institutionalized belief in the idea that "Science" subjects are "harder" than other subjects and it is a "risk" one takes by gambling and venturing in those areas. In other words, there is no guarantee that one will survive the rigor of the "sciences". In fact, the natural/physical sciences are also referred to as the "hard" sciences, a reference that reinforces the institutionalized belief of the near-impossibility of the "sciences". Yet, the "hard" part refers to the fact that the natural sciences deal with concrete objects, for example machines, animals, chemicals, physical tools; tangible things we can see, feel, touch and test.

\section{Discussion and Conclusion}

Most institutions have invested immensely into building campus student learning communities, freshman focus groups, on-line communities, and support for fraternity groups to enhance students' interest in staying enrolled across campuses. Learning communities are a group of individuals who share common courses and academic interests. Learning communities can take many forms. According to Smith (2001) the learning community approach fundamentally restructures the curriculum, and the time and space of students. Many different curricular restructuring models are being used, but all of the learning community models intentionally link together courses or coursework to provide greater curricular coherence, more opportunities for active teaming, and interaction between students and faculty. Other efforts include encouraging faculty to use interactive instruction, inquiry-based laboratories, and project-based and/or problem-based strategies as well as evidence-based instruction. Additionally, most high schools are encouraging more and more students to enroll in Advanced Placement (AP) and International Baccalaureate (IB) Mathematics and science programs.

One of the major causes of students' lack of appreciation of science careers has been a lack of knowledge of what science involves (Cleaves, 2005). What should institutions do to change students' perceptions toward mathematics and physical sciences? What should institutions do to help students make informed career choice decisions? Would exposing students to practicing scientists through internships help to shape their view of the sciences? Would making science activity-based in students' early ages make a difference? Is the quality of teaching a factor in this puzzle?

Also what has changed in the way professors teach STEM programs today? Is there something wrong with STEM education? Would establishing the link between science in university and industry change the matrix by exposing students to physical science-related careers? Would the "one-size-fits-all" approach work for all students in different academic disciplines? Does reviewing orientation activities make a difference? Would providing career-specific or program-specific orientation shape students' view of their choice for STEM programs? 
Recently, entrance and pre-requisites requirements have been adjusted through enrichment programs, innovative outreach, recruiting, and retention programs to increase enrollment rates (Davis, Yeary, \& Sluss, 2012). However, adjusting entrance requirements has not translated into increased completion rates. What are the fundamental differences between today's and 1950's college students' characteristics? Do changing demographics have any bearing on the generation of students enrolling in college today? What are students looking for in higher education today? One of the major drivers of students' choice of STEM careers was the salary differentials among graduates in all disciplines, but that does not seem to be the case in today's society. Presently, student self-efficacy is the prominent determinant for choosing a major field of study, and for student persistence.

Today, the major attractors to STEM courses are mostly pre-professional programs that require physical science as pre-requisite. This brings us to another piece of the puzzle. Do these students have interest in the classes at all? If not, are they adequately prepared to take those classes? What should instructors have to do to motivate these students to consider pursuing STEM programs? Based on these questions, and the review above, we offer further suggestions as indicated below.

\subsection{Support for Teachers of STEM Subjects}

Professional development plays a pivotal role if any significant changes are to be made in education. Educators are generally expected to keep abreast of the important advances occurring in education including remaining current on the increasing amount of pedagogical and content area research. Studies have shown that teachers who participate in sustained professional development activities which are grounded in content-specific pedagogy linked to new curriculum they are learning to teach are likely to have better results for their students (Wiley \& Yoon, 1995). A report by Wei, Darling-Hammond, Andree, Richardson, and Orphanos (2009) showed that states like North Carolina have posted largest student achievement gains in mathematics and reading scoring above the national average after introducing major changes which included teacher mentoring and ongoing professional development. This shows that ongoing professional development for teachers also plays a pivotal role in student achievement. Thus policies that seek to promote teacher professional development may help improve student success especially among STEM subjects.

While it is important to provide resources for STEM programs, it is equally important to provide professional development for faculty of STEM programs. Professional development of STEM teachers does not need to be offered outside the teachers' contractual time. Some of the cost-effective measures that schools can adopt to provide professional development of teachers include: (a) encouraging discipline-centered learning communities, (b) peer mentoring, and (c) team-teaching among faculty in STEM related disciplines.

Joint efforts in developing high school STEM curriculum could help bridge the current gap in STEM knowledge of incoming freshmen. Having a fair amount of overlap between 12th grade and college freshmen curricula would promote the ideal rigor for high school STEM education needed for student success in college. In addition, learning communities projecting STEM awareness can be held during lunch (brown bag meetings) as well as online via blogs or wikis. Furthermore, this platform can also be used as a springboard to spearhead collaboration between college/university faculty and high school, and post-school teachers, or can be between high school and post high school teachers. According to Edgcomb et al. (2010), learning communities have the ability to break the isolation of scientific discovery since they allow students to see their part within the scientific community as an important stepping stone into their future.

\subsection{Providing Necessary Support to STEM Students}

Some of the resources that can be provided to support STEM students include: (a) after school STEM programs, (b) targeted orientation programs, (c) early encouragement and support, and (d) student learning communities. Studies have shown that attending STEM afterschool programs improves attitudes toward STEM fields and careers, increases STEM knowledge and skills, and students have a higher likelihood of graduation and pursuing a STEM career (Afterschool Alliance, 2011). According to pre- and post-program surveys, programs such as Communication, Science, Technology, Engineering and Mathematics (CSTEM), For Inspiration and Recognition of Science and Technology (FIRST), Operation SMART, Science Club for Girls (SCFG), Student Science Enrichment Program (SSEP), TechBridge, Tech Corps, and TechREACH have been reported to have shown increased interest, self-confidence or positive attitudes towards STEM fields among their participants (Afterschool Alliance, 2011).

Students entering STEM programs should be encouraged to enroll into orientation courses which could be for a week or for a semester. At some institutions, student orientation programs only last for a week, and are usually completed before classes begin. The intent of these programs is to teach students study skills, time management 
skills, setting realistic expectations for coursework, developing supportive peer and mentor relationships, and adjusting to campus life. However, the classes will be quite diverse-students from various programs taking the same orientation course are unlikely to fully benefit from these "town-hall-like" programs as intended.

In some circumstances, students often meet their program professors for the first time in their second year, while the first academic year is reserved for other courses outside their major field of study. Some students may have lost interest in their first choice programs, or may have withdrawn from the college or changed their majors before meeting the academic practitioners in the programs they initially intended to pursue. Thus, intervention through orientation programs would be a worthwhile investment for many educational institutions. Faculty from each discipline need to be involved in these programs to allow students to understand specific expectations of each program.

In addition, early social persuasion, early teacher-parent encouragement, and emotional arousal would help to cultivate students' interest in STEM education. According to Chen and Soldner (2013), a student's choice of major is strongly dependent on parental and peer influences. Students' choice of majors is also strongly dependent on parental and peer influences. Students need to be encouraged to form STEM learning communities, where on a regular basis, they would get a chance to interact with STEM practitioners. These could be through peer mentoring programs or near-peer mentoring whereby new students may learn from more advanced ones. Near-peer mentors help bridge the sometimes-wide communication gap between students and faculty and also promotes early development of communication skills which can also potentially add value to the mentors (Edgcomb et al., 2010).

\subsection{Changes to Institutional Practices}

While freshmen STEM attrition rates are also related to high school achievement such as Grade Point Average (GPA) and the level of Mathematics courses completed (Chen \& Soldner, 2013), the process of entrant screening may drop talented students who may not have had a good high school learning experience. Better screening methods should be used to identify and offer alternative paths to prospective academically underprepared students. However, these programs have their downside. Students who take many of these preparatory courses take longer to complete their programs, and will incur more financial debt, as well as adding more costs to the institutional operating budget. Also, for colleges with boarding accommodation, it creates an accommodation crisis if enrollment in regular programs is maintained.

For effective implementation of STEM programs, there is need to effect some changes in institutional policies and practices and these include rigorous screening of students, providing support to students, examine course loads for STEM students. Through a rigorous screening process, students who may not have the necessary background and skill to succeed in STEM programs will be dropped. However, the decision to accept the students should not be based on one screening approach but multi-pronged approaches including aptitude, ability and interest. There are interest inventories available online free of charge, for example, Michigan State Area Schools-Student Interest Survey, Know Your Students, Education World-First Day of School Survey, and Interest Inventory. Institutions can provide a number of incentives to encourage students to stay in STEM programs. These may include extra credit work, reducing course loads and duration of STEM programs, and acknowledging participation in STEM programs. It needs to be noted that any reduction in course load and duration of the program should not compromise the quality and rigor of the STEM program.

Highly motivated students are likely to develop positive attitudes toward the course and succeed. Thus, one way to motivate students' attitudes is for the faculty to devise methods to make their courses more interesting. These include continuously improving teaching styles to accommodate the changing diversity in students' learning styles, and by constantly highlighting the relevance of the course to their everyday lives. Other efforts should include creating a learning environment that motivates students to enjoy learning the course. Faculty continuous self-assessment of their teaching effectiveness on all student teaching and evaluation instruments would help to identify areas that require improvement in order to increase students' persistence. For example, institutions can encourage and support both formal and informal input on STEM programs from the students. This kind of data can be used to address some problems before they get out of hand.

As noted above, the major issues shaping students' attitudes toward STEM can be personal, institutional, or external practices. The highest attrition rates come from science students who typically drop out when their hopes for academic success fade. Developing programs that influence students' attitudes positively towards STEM programs may well increase completion and persistence rates in STEM programs. In addition, addressing Mathematics problems will reduce attrition rates in physical sciences. These should include translating Mathematics concepts meaningful, real-life applications to assist students in relating the Mathematics concepts 
to the real-world context. The middle and high school curricula needs to be reviewed and realigned with college STEM entry needs. In addition, peer mentoring programs in STEM disciplines need improvements.

\section{Recommendations}

Drop-outs remain a major challenge in STEM education, and most institutions do not have the mechanisms in place to identify the warning signs for dropouts or switch-outs. Central to solving the issue of low enrollment rate and attrition of STEM students is the ability of institutions to collectively develop critical policies and practices that encourage students' enrollment and persistence during their participation in STEM programs. The need to understand the demands of the learners, but still maintain high learning and grading standards, is essential. Early intervention can be strengthened by understanding the students' needs, expectations in the course, academic challenges (areas where they need immediate help), what makes them persist to graduation, etc. Mid-semester/term grades are commonly used to assess the likelihood of a student to persist in their course, but institutions often miss the most important part of the student feedback that could help in making the necessary and timely adjustments or improvements. Thus we offer the following three main recommendations: 1) Change institutional practices. There are several practices that institutions can revisit. For instance, using other feedback-soliciting methods aimed at understanding the needs of the students well before early grade reports. For example, surveys from these students would provide a lead to attractors in these programs which may not be available in STEM fields. Such methods could involve early reflection papers or early course surveys; 2) Provide necessary support to STEM students. This could be in the form of student peer mentoring programs. These programs require a sustainable source of funding to compensate student mentors. Institutional funding challenges for such programs can be alleviated through collaboration between STEM programs and private organizations. The collaborations also help to strengthen bridges between STEM faculty and corporate organizations, which is fundamental to the training and placement of STEM graduates. In addition, teachers should seek funding from Foundations and local private funding agencies; and 3) Immersive professional development of teachers. This needs to be done systematically and tailor-made to STEM teachers by conducting a needs assessment of the STEM teachers and then designing programs that address the identified needs. Also, there is need to address programming issues such when to conduct the professional development, duration of programs, and incentives for participating in the programs. It's also beneficial to include administrators in the professional development programs to ensure support for the STEM teachers.

\section{References}

Afterschool, A. (2011). STEM learning in afterschool: An analysis of impact and outcomes. Retrieved from http://www.afterschoolalliance.org/STEM-Afterschool-Outcomes.pdf

Bandura, A. (1978). Self-efficacy: Toward a unifying theory of behavioral change. Advances in Behaviour Research and Therapy, 1(4), 139-161. https://doi.org/10.1016/0146-6402(78)90002-4

Bandura, A., \& Locke, E. A. (2003). Negative self-efficacy and goal effects revisited. The Journal of Applied Psychology, 88(1), 87-99. https://doi.org/10.1037/0021-9010.88.1.87

Berdahl, R. M. (1995). Educating the whole person. In A. G. Reinarz, \& E. R. White (Eds.), Teaching through academic advising: A faculty perspective (pp. 5-12). San Francisco, CA: Jossey-Bass. https://doi.org/10.1002/tl.37219956204

Bong, M., \& Skaalvik, E. M. (2003). Academic self-concept and self-efficacy: How different are they really? Educational Psychology Review, 15(1), 1-40. https://doi.org/10.1023/A:1021302408382

Burroughs Wellcome Fund. (2010). Student science enrichment program evaluation activities. Retrieved from http://www.bwfund.org/grant-programs/science-education/student-science-enrichment-program

Chalmers, A. F. (2013). What is this thing called science (4th ed.). Queensland, Australia: University of Queensland Press \& Hackett Publishing Company, Inc.

Chen, X., \& Soldner, M. (2013). STEM Attrition: College students' path into and out of STEM fields (NCES 2014-001). Retrieved from http://nces.ed.gov/pubs2014/2014001 rev.pdf

Cheryan, S., Master, A., \& Meltzoff, A. N. (2015). Cultural stereotypes as gatekeepers: Increasing girls' interest in computer science and engineering by diversifying stereotypes. Frontiers in Psychology, 6(FEB). https://doi.org/10.3389/fpsyg.2015.00049

Cleaves, A. (2005). The formation of science choices in secondary school. International Journal of Science Education, 27(4), 471-486. https://doi.org/10.1080/0950069042000323746 
Colvin, J. W., \& Ashman, M. (2010). Roles, risks, and benefits of peer mentoring relationships in higher education. Mentoring \& Tutoring: Partnership in Learning, 18(2), 121-134. https://doi.org/10.1080/13611261003678879

Correll, S. J., Seymour, E., \& Hewitt, N. M. (1997). Talking about leaving: Why undergraduates leave the sciences. Contemporary Sociology, 26, 644. https://doi.org/10.2307/2655673

Dancy, M. H., \& Henderson, C. (2008). Barriers and Promises in STEM Reform. Barriers and Promises in STEM Reform (Vol. 1).

Davis, C. E., Yeary, M. B., \& Sluss, J. J. (2012). Reversing the trend of engineering enrollment declines with innovative outreach, recruiting, and retention programs. IEEE Transactions on Education, 55(2), 157-163. https://doi.org/10.1109/TE.2011.2157921

Edgcomb, M. R., Crowe, H. A., Rice, J. D., Morris, S. J., Wolffe, R. J., \& McConnaughay, K. D. (2010). Peer and near-peer mentoring: Enhancing learning in summer research programs. CUR Quarterly, 31(2), 18-25.

Garnham, C., Kaleta, R. J., \& Sudzina, M. (2003). Preparing for and teaching hybrid courses. In EDUCAUSE. Retrieved from http://www.educause.edu/library/resources/preparing-and-teaching-hybrid-courses

Geary, D. C. (2013). Early foundations for mathematics learning and their relations to learning disabilities. Current Directions in Psychological Science, 22(1), 23-27. https://doi.org/10.1177/0963721412469398

Giffi, C., Dollar, B., Drew, M., McNelly, J., Carrick, G., \& Gangula, B. (2015). The skills gap in U.S. manufacturing 2015 and beyond. from http://www2.deloitte.com/content/dam/Deloitte/us/Documents/manufacturing/us-pip-the-manufacturing-ins titute-and-deloitte-skills-gap-in-manufacturing-study.pdf

Griffith, A. L. (2010). Persistence of women and minorities in STEM field majors: Is it the school that matters? Economics of Education Review, 29(6), 911-922. https://doi.org/10.1016/j.econedurev.2010.06.010

Hershner, S. D., \& Chervin, R. D. (2014). Causes and consequences of sleepiness among college students. Nature and Science of Sleep. https://doi.org/10.2147/NSS.S62907

Hewson, S. (2011). The mathematical problems faced by advanced STEM students. In NRICH enriching mathematics. Cambridge, U.K. Retrieved from http://nrich.maths.org/6458

Ingersoll, R. (1998). The Problem of Out-of-Field Teaching. PHi Delta Kappan, 773-776.

LaFee, S. (2003). Professional learning communities. School Administrator, 60, 6-12. Retrieved from http://login.ezproxy1.lib.asu.edu/login?url=http://search.ebscohost.com/login.aspx?direct=true\&db=eft\&A $\mathrm{N}=507826765 \&$ site $=$ ehost-live

Mattern, K., Radunzel, J., \& Westrick, P. (2015). Development of STEM readiness benchmarks to assist educational and career decision making. Retrieved from http://files.eric.ed.gov/fulltext/ED558031.pdf

Miller, R. (2000). Creating learning communities: Models, resources, and new ways of thinking about teaching and learning. Brandon, VT: The Foundation for Educational Renewal, Inc.

Morrison, T., Maciejewski, B., Giffi, C., DeRocco, E. S., McNelly, J., \& Carrick, G. (2011). Boiling point? The

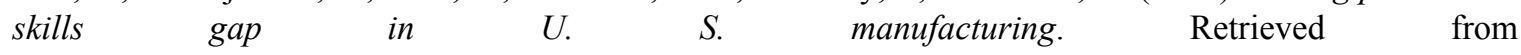
http://www.themanufacturinginstitute.org/ /media/A07730B2A798437D98501E798C2E13AA.ashx

Morton, B. A., Peltola, P., Hurwitz, M. D., Orlofsky, G. F., \& Strizek, G. A. (2008). Education and certification qualifications of departmentalized public high school-level teachers of core subjects: Evidence from the 2003-04 schools and staffing survey. In Statistical Analysis Report. National Center for Education Statistics. Retrieved

from http://search.ebscohost.com/login.aspx?direct=true\&db=eric\&AN=ED502467\&site=ehost-live

National Science Board. (2008). Science and engineering indicators 2008. Science and Engineering Indicators, $1-47$.

National Science Foundation. (2014). Science and engineering indicators 2014. NSF, National Science Foundation, 1, 14-60.

NGSS. (2013). NGSS Front Matter. Retrieved from http://www.nextgenscience.org/sites/ngss/files/Final Release NGSS Front Matter - 6.17.13 Update_0.pdf

Noel-Levitz. (2013). National Freshman Attitudes Report: Exploring college readiness among today's entering freshmen. Cedar Rapids, 
https://www.noellevitz.com/papers-research-higher-education/2013/2013-national-freshman-attitudes-repor $\mathrm{t}$

Ost, B. (2010). Differences in persistence patterns between life and physical science majors: The role of grades, peers, and preparation. Economics of Education Review, 29(6), 923-934. https://doi.org/10.1016/j.econedurev.2010.06.011

Popham, W. J. (2005). All about accountability/students' attitudes count. Educational Leadership, 62(5), 84-85. Retrieved

from http://www.ascd.org/publications/educational-leadership/feb05/vol62/num05/Students'-Attitudes-Count.asp $\mathrm{x}$

Rapoport, A. (1973). Uses of mathematics outside the physical sciences. SIAM Review, 15(2), 481-502. https://doi.org/10.1137/1015068

Riffell, S. K., \& Sibley, D. F. (2004). Can hybrid course formats increase attendance in undergraduate environmental science courses? Journal of Natural Resources and Life Sciences Education, 33, 16-20. Retrieved from http://www.lon-capa.org/papers/E03-16.pdf

Rittmayer, A. D., \& Beyer, M. E. (2008). Overview: Self-efficacy in STEM. Retrieved from http://www.engr.psu.edu/awe/misc/ARPs/ARP_SelfEfficacy_Overview_122208.pdf

Rogers, W. D., \& Ford, R. (1997). Factors that affect student attitude toward biology. Bioscene, 23(2), 3-5. Retrieved from http://acube.indstate.edu/volume_23/v23-2p3-5.pdf

Ryan, R., \& Deci, E. (2000). Intrinsic and extrinsic motivations: Classic definitions and new directions. Contemporary Educational Psychology, 25(1), 54-67. https://doi.org/10.1006/ceps.1999.1020

Sithole, A., Kibirige, J., Mupinga, D. M., \& Chiyaka, E. T. (2016). Applying alternative teaching methods to impart a rounded, Liberal Arts and Sciences (LAS) education: Students' reflections on the role of magazines as instructional tools. Education and Practice, 7(33), 176-182.

Sklar, J. (2014). The impact of change of major on time to bachelor's degree completion with special emphasis on STEM disciplines : A multilevel discrete-time hazard final report.

Smith, B. L. (1993). Creating learning communities. Liberal Education, 79(4), 32-36.

Smith, B. L. (2001). The challenge of learning communities as a growing national movement. Conference, 1 , $1-9$.

STEM Market Impact, LLC. (2010). Challenges facing STEM education. In STEM reports. Retrieved from http://www.stemreports.com/challenges-facing-stem-education/

Stinebrickner, T. R., \& Stinebrickner, R. (2007). The Causal Effect of Studying on Academic Performance (No. NBER Working Paper No. 13341). https://doi.org/10.3386/w13341

Sunstein, C. R. (2013, July 13). Why U.S. students don't major in science. In Bloomberg View. New York City, NY. Retrieved from http://www.bloombergview.com/articles/2013-07-17/why-american-students-don-t-major-in-science

Tai, R. H., Qi-Liu, C., Maltese, A. V., \& Fan, X. (2006). Career choice. Planning early for careers in science. Science (New York, N.Y.), 312(5777), 1143-1144. https://doi.org/10.1126/science.1128690

Wei, R. C., Darling-Hammond, L., Andree, A., Richardson, N., \& Orphanos, S. (2009). Professional learning in the learning profession: A status report on teacher development in the U.S. and abroad. National Staff Development Council, $162 . \quad$ Retrieved from http://www.becker.k12.mn.us/sites/beckerschools/files/departments/2012/NSDCstudytechnicalreport2009_ 0.pdfinfiles/24/NSDCstudytechnicalreport2009-PD-use.pdf

Wiley, D., \& Yoon, B. (1995). Teacher reports of opportunity to learn: Analyses of the 1993 California Learning Assessment System. Educational Evaluation and Policy Analysis, 17(3), 355-370. https://doi.org/10.3102/01623737017003355 


\section{Copyrights}

Copyright for this article is retained by the author(s), with first publication rights granted to the journal.

This is an open-access article distributed under the terms and conditions of the Creative Commons Attribution license (http://creativecommons.org/licenses/by/4.0/). 